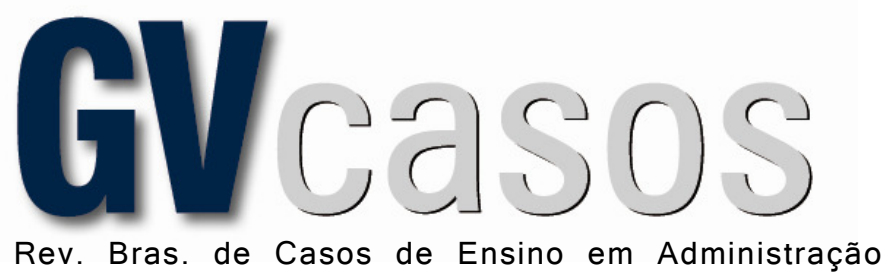

DOI: http://dx.doi.org/10.12660/gvcasosv10n2c13

\title{
OUTSOURCING: MANTER FROTA PRÓPRIA OU TERCEIRIZAR OS SERVIÇOS DE TRANSPORTES?
}

Outsourcing: do we use our own fleet or delegate transport services to thirdparties?

\author{
ADRIANo STADLER - adriano.stadler@ifpr.edu.br \\ Instituto Federal do Paraná - Curitiba, PR, Brasil \\ ZÉLIA HALICKI - zeliahalicki@gmail.com \\ Universidade Cesumar - Maringá, PR, Brasil
}

\begin{abstract}
Resumo
O caso relata o dilema de Lorena Ribeiro, filha única do fundador da Khemeia Brasil, que vivenciou a experiência de sua empresa se tornar pouco produtiva com métodos que não atendiam às necessidades dos consumidores. Os dados deste caso foram recriados e adaptados a partir de entrevistas com a herdeira da Khemeia Brasil. O caso tem por objetivos: 1) apresentar a terceirização como alternativa na gestão de frotas; 2) refletir sobre a eficácia das estratégias de logística na gestão de pequenas e médias empresas; 3) estabelecer alternativas para a tomada de decisão quanto à terceirização de serviços de transporte.
\end{abstract}

Palavras-chave: Terceirização, logística, tomada de decisão.

\begin{abstract}
The case presents the dilemma of Lorena Ribeiro, the founder's only daughter, who experienced her company becoming unproductive with methods that did not meet the needs of consumers. The data of this case were recreated and adapted from interviews with the heiress of KhemeiaBrasil. The case has as objectives: 1) to present the outsourcing as an alternative in the company's fleet management; 2) to reflect on the effectiveness of logistics strategies in the management of small and medium-sized enterprises; 3) to establish alternatives for the decision making regarding the outsourcing of transport services.

Keywords: Outsourcing. Logistics. Decision making..

\section{Introdução}

Lorena Ribeiro, uma jovem economista, está acostumada com desafios em sua vida pessoal e profissional. Aos 15 anos, começou a trabalhar na empresa da família para que, quando terminasse o ensino regular, tivesse a oportunidade de estudar nos Estados Unidos da América (EUA). Assim, aprendeu na prática o que é gerenciar uma indústria de médio porte.

Iniciou fazendo fotocópias e levando o malote de pagamentos aos bancos, e, antes de obter a maioridade, já negociava com fornecedores, realizava as compras e atendia clientes. Decisão difícil foi deixar aquele trabalho que aprendeu a amar para estudar fora do País. Decidida a realizar seu sonho, embarcou para San Antonio, no Texas-EUA, para cursar a faculdade de Administração de Empresas. No final de 2016, cinco anos mais tarde, e com uma grande bagagem acadêmica, pessoal e profissional, voltou para o Brasil e encontrou a empresa de seu pai numa delicada situação financeira.
\end{abstract}


Em 2017, o Brasil se encontrava em meio a uma instabilidade política e econômica, e a Khemeia Brasil enfrentava dificuldades para manter as atividades produtivas com o mesmo quadro de pessoal, diante do mercado apresentando novos concorrentes com qualidade e preço inferiores aos de seus produtos. Esses foram alguns fatores que Lorena encontrou na retomada de suas atividades na empresa familiar. Ribeiro:

Alguns dias após seu retorno, a crise ficou evidente num diálogo com seu pai, Bonifácio

- Mas, pai, como a empresa chegou nesta situação? Por que nas minhas visitas à nossa família, ou nas conversas por telefone, o senhor não me alertou sobre as dificuldades?

- A crise chegou para todos! Aqueles que conseguiram manter suas portas abertas já são vitoriosos, minha filha.

- Entendo, mas poderíamos ter conversado sobre isso, pai! Sou sua filha única, e poderia tentar ajudar, mesmo estando longe. Eu poderia até ter voltado antes de lá.

- Filha, você me ajudará muito voltando a trabalhar ao meu lado na direção da empresa, e me ajudando a tomar decisões importantes, como "enxugar a máquina".

Semanas após o retorno ao Brasil, Lorena voltava às suas atividades na Khemeia Brasil, pronta para colocar seus conhecimentos em prática e lidar com a personalidade generosa e patriarcal de Bonifácio, característica essa a mais desafiadora para que Lorena implantasse as ferramentas de gestão necessárias para a permanência da empresa no mercado.

\section{A empresa}

Khemeia significa química na língua grega, e é uma indústria que está voltada para o desenvolvimento, fabricação, envase e comercialização de produtos químicos automotivos, industriais e para construção civil, como: a) aerossóis: desengripante, silicone, descarbonizante, desengraxante, antiderrapante, limpa-contato, adesivos, inseticidas; b) líquidos: fluido para freios, aditivo para radiador; c) pastosos e outros: limpa-para-brisa, antiembaçante, aromatizante, limpapneu, silicone, pasta para mãos etc.

Fundada em julho de 1994 e localizada na cidade de Castro, no estado do Paraná, a Khemeia Brasil inicialmente atendia somente à subsidiária brasileira de uma empresa alemã, desenvolvendo e produzindo alguns itens da linha automotiva. Com o passar do tempo, adquiriu a confiança de outras empresas nacionais e multinacionais. Em decorrência disso, o quadro de colaboradores aumentou, e, consequentemente, os investimentos em maquinário, tecnologia e instalações tornaram-se indispensáveis.

Objetivando a adequação dos produtos a padrões internacionais de qualidade, a empresa, por meio de seus colaboradores, aperfeiçoou seu sistema de qualidade, certificando-se com base na norma ISO 9001, restando claro que é necessário constantemente aprimorar-se, de modo a atender sua política de qualidade.

A empresa também possui certificação com base na norma ISO 14001, visando desenvolver constantemente, em seus colaboradores, na comunidade e partes interessadas, a consciência ambiental, por meio da redução da poluição, preservação do meio ambiente e conservação dos recursos naturais. A obtenção dessa certificação foi a grande contribuição de Lorena para a empresa da família, antes de sua viagem para estudos nos EUA.

Ainda à época, foi definida a missão da empresa: "Identificar e atender as reais necessidades dos clientes com total disponibilidade, comprometimento e foco no desenvolvimento humano". Já a visão é "ser reconhecida por oferecer soluções que superam as expectativas de resultado".

A hierarquia da empresa é verticalizada, iniciando pelo proprietário, Bonifácio, e composta também por gerência, supervisores, analistas, encarregados, operadores e assistentes. A empresa, no 
momento em que Lorena retoma sua atividade, conta com 87 colaboradores, atuando o setor produtivo em dois turnos.

O quadro de funcionários é enxuto, atuando com um gerente geral da fábrica, que também acumula a função de gerência comercial. Possui um gerente administrativo e um financeiro, além de gerentes técnicos e de qualidade. $O$ setor de logística tem 23 funcionários entre almoxarifado, expedição e transporte (motoristas). Vale ressaltar que os serviços de refeitório, portaria, segurança patrimonial, conservação e limpeza já são terceirizados.

O serviço de transporte atualmente é realizado por frota própria, gerida pelos colaboradores do departamento de Logística. A política da empresa é priorizar entregas e coletas com a frota, de modo que a operação com veículos terceirizados seja utilizada apenas em casos de necessidade. A demanda de cargas da empresa entre entregas e coletas, no período de janeiro a setembro de 2016, teve uma média de 98 cargas por mês, das quais $72 \%$ foram realizadas pela própria frota, e $28 \%$, por terceiros contratados.

Por ser do segmento de produtos químicos perigosos, a empresa cumpre todos os requisitos aplicáveis ao transporte rodoviário de produtos perigosos, entre eles a determinação da Norma Brasileira Regulamentadora (NBR) 9735 - Conjunto de equipamentos para emergências no transporte terrestre de produtos perigosos, que estabelece que todos os veículos para esse tipo de carga devem portar o kit de emergência. Além disso, os motoristas são capacitados com o curso de Movimentação de Produtos Perigosos (MOPP), que é obrigatório para esse tipo de carga. São diversos os órgãos que regulamentam o transporte de produtos perigosos, tais como Agência Nacional de Transportes Terrestres (ANTT), exército, órgãos ambientais estaduais, Instituto Brasileiro de Meio Ambiente (Ibama), polícia civil, polícia federal, entre outros.

\section{$O$ início dos conflitos na empresa familiar}

O primeiro grande dilema que Lorena precisa enfrentar em sua volta está ligado à frota de veículos que a empresa possui, a qual tem apresentado graves problemas de gestão e manutenção, bem como ocupa número expressivo de funcionários para a operação. Questionado por diversas vezes pelos gerentes da fábrica, Bonifácio sempre foi resistente à ideia de terceirizar a frota, gerando algumas situações de conflito. Assim, Lorena retoma a discussão:

- Pai, talvez terceirizar toda a distribuição de nossos produtos possa ser uma solução. Já temos quase $1 / 3$ das entregas realizadas por terceiros, isso seria um processo natural.

- A distribuição não é o problema da empresa, precisamos abrir novos mercados, as vendas é que estão fracas. atualmente.

- Mas veja bem: não temos estrutura para aumentar a produção com a frota que temos

- Os motoristas dependem deste emprego, sou eu que garanto o pão de cada dia dessas famílias, minha filha!

O discurso patriarcal e generoso de Bonifácio se expressa em suas atitudes na contratação e manutenção desses funcionários, desenvolvendo, inclusive, laços de amizade com os empregados e suas famílias.

Lorena sugere ao pai que sejam dispensados os motoristas e todos os serviços sejam terceirizados, porém, ao questioná-lo sobre se essa alternativa era a mais viável, ele responde que não fez nenhum cálculo, e não acredita que a terceirização possa ajudar a reduzir as despesas. Lorena, então, começa sua investigação na empresa em busca do levantamento de custos dos caminhões, relação de custos de fretes terceirizados, valores gastos com os motoristas e também dos feedbacks dos clientes sobre os serviços próprios. 
Após colocar em questão a possibilidade de terceirização dos transportes, Lorena sentiu-se um tanto quanto amargurada, pois, provavelmente, a próxima medida a ser tomada seria terceirizar a frota e, assim, vender os caminhões próprios, o que acarretaria demissão dos motoristas.

Tendo ela sempre mantido bom relacionamento com todos os funcionários, tinha conhecimento de que um dos motoristas tinha dois filhos em idade escolar, e outro tinha um casal de gêmeos, e sua esposa estava grávida. Imediatamente lhe veio à mente a situação pela qual poderiam passar os filhos dos motoristas, caso estes viessem a ser desligados da empresa. Mesmo sabendo da competência dos funcionários, Lorena tinha conhecimento de alguns motoristas que, mesmo tendo experiência, estavam tendo dificuldades em conseguir emprego.

Assim, Lorena imediatamente buscou seus arquivos sobre os custos dos transportes, onde constavam detalhadamente os gastos com cada veículo, pois sempre tomou o cuidado de fazer as planilhas com o maior número de detalhes para quaisquer dúvidas que surgissem, bem como para sempre estar acompanhando se os veículos estavam nas mesmas margens de gastos.

Lorena logo percebeu que o levantamento de custos de transporte próprio em comparação com terceiros não era tão complicado assim. Pelo fato de a empresa já utilizar diversos serviços subcontratados, já possuía uma tabela de valores (dos terceiros) para fretes para as principais regiões que atende. A partir do levantamento desses dados, Lorena começou a fase de cálculos para que, posteriormente, pudesse se reunir com seu pai para definir a melhor estratégia para a empresa.

\section{A tomada de decisão na Khemeia Brasil}

Lorena convocou uma reunião com o gestor da frota na qual lhe propôs a terceirização dos serviços de transporte e entrega dos produtos, com o intuito de diminuir os custos e, consequentemente, aumentar a competitividade. O gerente de Logística afirmou que, ao contrário do que Lorena pensava, terceirizar os serviços de transporte e distribuição faria os custos aumentarem.

Percebendo que havia desconhecimento do gestor acerca dos custos logísticos, ela resolveu desenvolver um estudo comparativo entre as duas possibilidades (manter a frota própria ou terceirizar). $\mathrm{O}$ fato de ter se formado recentemente em Administração de Empresas facilitou o desenvolvimento do estudo, pois, durante o curso, aprendeu a elaborar detalhadamente planilhas de custos, o que se tornou um hábito.

Algumas dúvidas cercavam os pensamentos de Lorena, como: a empresa está disposta a flexibilizar parte da capacidade financeira e investir em sua própria estrutura de transporte? Ou deve se comprometer com um arranjo contratual de curto, médio ou longo prazo? Há outros critérios além da otimização de custos?

Porém, em função de as decisões de Bonifácio serem sempre demasiadamente emocionais, deveria levar em consideração os impactos que uma decisão poderia acarretar no resultado final. Somente resultados financeiros e estatísticos não garantiam uma situação confortável no futuro. Fazia-se necessário analisar também algumas questões subjetivas, como impacto no ambiente organizacional, reação dos clientes, treinamento do terceirizado, impacto social de uma mudança no quadro de pessoas e, principalmente, a instabilidade que a decisão da herdeira do negócio traria ao restante da organização ao tomar uma decisão contrária aos valores e princípios do fundador.

Então Lorena realizou o levantamento dos dados necessários de janeiro a setembro de 2017 , com os quais foram elaboradas as planilhas, conforme Figura 1. Por meio do estudo, foram verificados todos os gastos pertencentes à frota própria, assim como os possíveis gastos com frotas terceirizadas, a partir de tabela de preços disponibilizada por terceiros que operam nos principais destinos dos produtos comercializados pela empresa em análise no presente caso. 
OUTSOURCING: MANTER FROTA PRÓPRIA OU TERCEIRIZAR OS SERVIÇOS DE TRANSPORTES? Adriano Stadler, Zélia Halicki

Figura 1. Custos da frota no período analisado

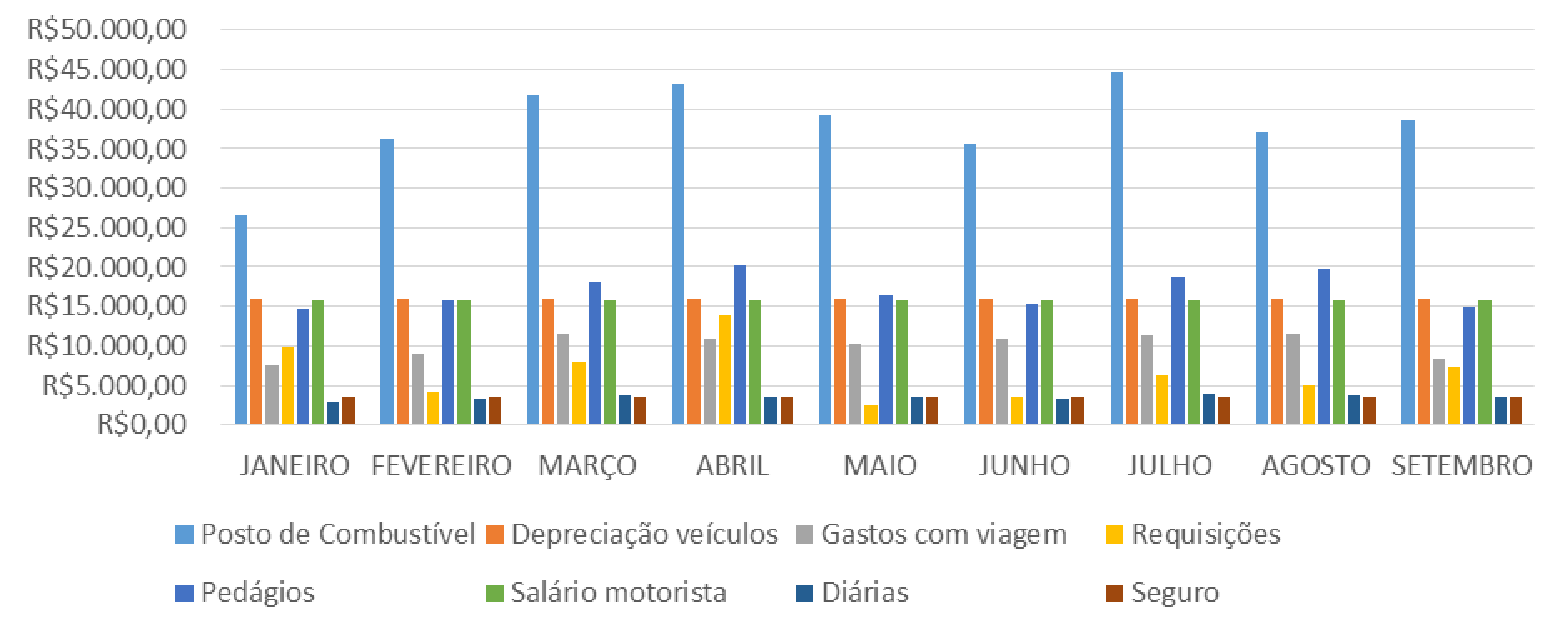

Fonte: Dados fornecidos pela empresa (2018).

Diante das informações coletadas, constatou-se que o grande desafio do setor de transporte era maximizar a eficiência e a eficácia sem comprometer a qualidade da execução dos serviços. Nessa abordagem, o esforço se concentraria em assegurar que o número certo de veículos realize os trabalhos pelo menor custo total, englobando a sua aquisição, despesas com pessoal, manutenção, combustível e despesas com sinistros dos veículos, além da substituição e disposição destes em relação à frota terceirizada.

Outro fator que traria vantagem para a empresa em caso da utilização de serviços da frota própria é a flexibilidade em relação ao controle dos destinos no sentido de eventuais alterações de rotas, seja para atender outro cliente ou mesmo para uma coleta de urgência. Portanto, essa autonomia possibilita maior agilidade em atendimento às necessidades do cliente e da empresa e a consequente redução de custos na operação.

Tabela 1. Simulação custos frota própria $X$ frota terceirizada

\begin{tabular}{|c|c|c|c|c|c|c|c|}
\hline \multirow[b]{2}{*}{ Jan } & Frota da empresa & \multicolumn{2}{|c|}{ Frota terceirizada } & \multicolumn{2}{|c|}{$\begin{array}{c}\text { Economia s/ desconto } \\
\text { de impostos }\end{array}$} & \multicolumn{2}{|c|}{$\begin{array}{c}\text { Com desconto de } \\
\text { impostos }(21,25 \%)\end{array}$} \\
\hline & $\mathrm{R} \$ \quad 96.713,99$ & $\mathrm{R} \$$ & $151.830,00$ & $\mathrm{R} \$$ & $55.116,01$ & $\mathrm{R} \$$ & $32.263,88$ \\
\hline Fev & $\mathrm{R} \$ 103.659,55$ & $\mathrm{R} \$$ & $179.000,00$ & $\mathrm{R} \$$ & $75.340,45$ & $\mathrm{R} \$$ & $38.037,50$ \\
\hline Mar & $\mathrm{R} \$ 118.016,49$ & $\mathrm{R} \$$ & $205.700,00$ & $\mathrm{R} \$$ & $87.683,51$ & $\mathrm{R} \$$ & $43.711,25$ \\
\hline Abr & $\mathrm{R} \$ 126.800,62$ & $\mathrm{R} \$$ & $208.900,00$ & $\mathrm{R} \$$ & $82.099,38$ & $\mathrm{R} \$$ & $44.391,25$ \\
\hline Mai & $\mathrm{R} \$ 106.941,00$ & $\mathrm{R} \$$ & $180.500,00$ & $\mathrm{R} \$$ & $73.559,00$ & $\mathrm{R} \$$ & $38.356,25$ \\
\hline Jun & $\mathrm{R} \$ 104.233,55$ & $\mathrm{R} \$$ & $189.900,00$ & $\mathrm{R} \$$ & $85.666,45$ & $\mathrm{R} \$$ & $40.353,75$ \\
\hline Jul & $\mathrm{R} \$ 120.238,87$ & $\mathrm{R} \$$ & $220.600,00$ & $\mathrm{R} \$$ & $100.361,13$ & $\mathrm{R} \$$ & $46.877,50$ \\
\hline Ago & $\mathrm{R} \$ 112.243,97$ & $\mathrm{R} \$$ & $170.300,00$ & $\mathrm{R} \$$ & $58.056,03$ & $\mathrm{R} \$$ & $36.188,75$ \\
\hline Set & $\mathrm{R} \$ 107.945,22$ & $\mathrm{R} \$$ & $175.400,00$ & $\mathrm{R} \$$ & $67.454,78$ & $\mathrm{R} \$$ & $37.272,50$ \\
\hline TOTAL & R\$ 996.793,26 & $\mathbf{R} \$$ & 1.682.130,00 & $\mathbf{R} \$$ & 685.336,74 & $\mathbf{R} \$$ & $357.452,63$ \\
\hline
\end{tabular}

Fonte: Elaboração própria a partir dos dados levantados na empresa e nas tabelas de preços de prestadoras de serviços de transportes (2018). 
Após os levantamentos de dados, elaboração dos gráficos e planilhas, Lorena solicitou uma reunião com seu pai e fundador da Khemeia Brasil, Bonifácio, e demais gerentes da empresa, objetivando tomar a decisão.

Lorena iniciou a reunião relatando que, em sua formação acadêmica nos EUA, adquiriu muito conhecimento teórico e que, a partir de seu retorno à empresa, alguns questionamentos lhe vieram à mente, e suas reflexões buscaram trazer à tona as teorias aprendidas e como isso poderia ser aplicado à realidade da empresa de seu pai, que agora passava por dificuldades. Mas, ao mesmo tempo, também se preocupava em manter a cultura organizacional já estabelecida e manter o modelo de gestão praticado por seu pai desde a fundação da empresa.

Assim, Lorena indagou na reunião:

- Qual é a melhor opção para a empresa: manter a frota própria ou terceirizar?

- Será a redução de custos logísticos a melhor opção para a empresa?

- Quais impactos sociais, emocionais e de gestão a terceirização trará para a empresa?

- Quais consequências terá a decisão de terceirizar a frota? 